\title{
A CRIAÇÃO LITERÁRIA E O COTIDIANO
}

\author{
José Wellington Días Soares ${ }^{1}$
}

\begin{abstract}
Resumo: Este texto faz parte de uma pesquisa de doutoramento, em que analisamos aspectos do cotidiano e representações culturais em romances e crônicas de Machado de Assis e de Lima Barreto, correspondendo, portanto, ao espaço da cidade do Rio de Janeiro, entre os anos de 1881 e 1922. Neste momento, nosso objetivo é tão-somente desenvolver uma exposição/análise do argumento teórico que norteará a investigação. Com isso, manteremos um diálogo com a bibliografia de referência que trata sobre o cotidiano na concepção epistemológica (LUKÁCS, 1965, 1968; HELLER, 2008), e como objeto de análise para a compreensão da história (PRIORE, 1997; MATOS, 2002; CERTEAU, 2008; LANA, 2008). Logo, discutiremos o modo como o romance transfigura a realidade em ficção. Nesse sentido, o texto literário (sem negar sua função poética ou ficcional, que equivale a representar um mundo do ponto de vista estético) possibilita, devido à sua capacidade de plasmar uma complexidade de temas relacionados à realidade cotidiana das pessoas, vários recortes para o estudioso desenvolver relações com a vida social e com elementos históricos e culturais. Por isso, pode servir como uma fonte documental para o historiador desenvolver uma interpretação segura de acontecimentos passados, desde que ele faça as devidas relações com outras fontes e/ou a historiografia do assunto em interesse.
\end{abstract}

Palavras-Chave: Cotidiano. Literatura. História. Teoria.

\section{THE LITERARY CREATION AND THE EVERYDAY}

\begin{abstract}
This text is part of a P.H.D research inwhich we analyzed some aspects of the everyday and cultural representations in novels and chronicles by Machado de Assis and Lima Barreto, related to the city of Rio de Janeiro, between 1881 and 1922. Here, our main objective is the development of an exposition/analysis of the theoretical reasoning that will lead the investigation. Thus, we intend to establish a dialogue with the referential bibliography about the everyday in the epistemological conception (LUKÁCS, 1965, 1968; HELLER, 2008), and as object of study to the comprehension of history (PRIORE, 1997; MATOS, 2002; CERTEAU, 2008; LANA, 2008). In this way, we discuss how a novel is able to transfigure reality into fiction once poetical and fictional functions of a literary text are equivalent to represent a world from an aesthetics point of view. In this sense, the literary text provides several possibilities to a researcher to develop connections to the social life as also to historical and cultural elements. It happens because the literary text has the ability of shaping many themes that are related to people's daily routine. Thereby, literary texts appear as documental sources helping historians on the development of reliable
\end{abstract} ${ }^{1}$ Professor Adjunto do curso de Letras da FECLESC (Faculdade de Educação, Ciências e Letras do Sertão
Central) da UECE (Universidade Estadual do Ceará). Quixadá-Ceará. E-mail: wellington.soares@uece.br. 
interpretations of past events. Although, the historian must be aware of making the right relations to other sources as well as to the historiography about the subject of interest.

Key words: Everyday. Literature. History.

A literatura é impressionante, assim como a arte em geral, justamente porque pode nos apresentar, além de outros elementos, uma complexa imagem do cotidiano. Nela, existe a abordagem dos mais variados assuntos de maneira simples e descontraída, em alguns momentos, ou de forma complexa e concentrada, em outros. Dependendo da visão de mundo e da posição ideológica do escritor, essa abordagem pode nos levar, enquanto leitores, a refletir aquilo que é posto pelas classes dominantes ou fazer-nos ouvir as vozes que são caladas ao longo do tempo por pertencerem às classes menos favorecidas. Por isso, em meio ao fascínio da arte, é preciso lançar um olhar crítico sobre essa produção, porquanto ela tem uma imensa influência sobre as pessoas e pode, de alguma maneira, levá-las tanto à subversão de valores e normas como conceber determinados conceitos e dogmas que serão usados como meio de conformismo e aceitação da realidade.

Desse modo, a literatura pode além da sua finalidade estética, funcionar como um veículo de identificação de pessoas de um mesmo grupo, sendo utilizada para denunciar injustiças e conflitos, mas também pode fazer com que sejam naturalizados os discursos do mais forte sobre o mais fraco, da acomodação, e um discurso que não leve o leitor a refletir sobre o papel dele, enquanto agente social e responsável por atitudes coletivas. De um jeito ou outro, identificamos na arte literária, decerto, o estético como político conforme assinala Jacques Rancière (2005).

Como manifestação artística concretizada na articulação entre motivações políticas, históricas, sociais, econômicas, valorativas, culturais, enfim, entre motivações diversas que repercutem no fazer estético, a literatura não pode ser compreendida como objeto isolado, sem interferências do leitor, sem o conhecimento das condições de produção/recepção em que o texto foi produzido.

O texto literário é plural, marcado pela inter-relação entre diversos códigos (temático, ideológico, linguístico, estético etc.). Portanto, é um 
processo dialético que se passa da quantidade (natureza/cotidiano) à qualidade (humano), e um procedimento que depende da organização, isto é, depende de fatores objetivos/subjetivos, de decisões e escolhas.

Concordamos com Georg Lukács quando diz que "o movimento no qual o artista (e o romancista também é artista) reflete a realidade objetiva culmina, fixa-se, recebe forma no particular" (1968, p. 159). O fato de investigarmos a relação entre a ficção e o cotidiano não se limita à identificação desses fenômenos, mas, sobretudo, onde e como se inicia a imbricação entre ambos, ainda que sejam objetivações humanas diferentes.

$\mathrm{Na}$ sua obra mais importante, Georg Lukács afirma que "elcomportamiento cotidiano delhombre es comienzo y final al mismotiempo de toda actividade humana" (1965, p. 11), o que poderemos incluir, seguramente, a arte literária. E prossegue adiante: "Sólo a partir de esa dinâmica de la génesis, eldespliegue, la autonomia y la raiz enla vida de lahumanidad, puedenconseguirselas peculiares categorias y estructuras de lasreacciones científicas e artísticas delhombre a larealidad" (1965, p. 11).

A literatura, assim como o romance especificamente, possui também suas peculiaridades e estruturas, que estão vinculadas à realidade, ao cotidiano. Identificar e analisar a gênese desse processo é, ao mesmo tempo, compreender a criação literária como objeto concreto e histórico que parte do homem e, portanto, é imaginação e experiência a um só tempo. Onde e como termina esta e começa aquela, ou melhor, de que forma ambas se entrelaçam para formar imagens suscetíveis de entendimento para o receptor, é tarefa da nossa investigação.

Costuma-se entender a vida cotidiana como a experiência da existência ordinária, em que as pessoas praticam hábitos repetitivos. As atividades do dia-a-dia são executadas quase automaticamente, como se o sujeito fosse presa de seus próprios atos. Perdendo sua individuação, ele diminuiria sua autonomia e a capacidade de projetar antecipada e conscientemente suas ações do dia-a-dia. Entretanto, o fazer repetitivo das pessoas em sociedade não encontra seu princípio no cotidiano, sendo este já afetado por relações de força que o comprime e reduz suas possibilidades de experiências novas. 
Para compreendermos as relações cotidianas, nesse caso, é preciso considerar o tipo de sociedade em que o indivíduo interage social e politicamente com os outros e com o mundo de forma geral. Assim, é importante saber o que essa sociedade lhe oferece (economia, religião, cultura, símbolos, imaginário, instituições etc.) e como ele reage objetivamente a esses elementos. Além do que, o espaço em que o sujeito ocupa nessas relações, bem como o recorte temporal, faz parte do círculo cotidiano que se pretende estudar.

Os acontecimentos que a princípio não têm sentido e nem explicação, afetam de forma significativa os rumos da vida cotidiana em sociedade (LANA, 2008). Surge daí a experiência de vida das pessoas, pois elas, mesmo sem perceber, vão avançando para o novo e conservando o antigo, numa espécie de movimento dialético. Por meio de alguns acontecimentos, registrados e documentados em linguagem verbal ou não-verbal, podemos historicizar o cotidiano. Por ser complexo, volátil, fluido, não garante sua fixação, a não ser pela memória do povo, pelo imaginário, pela arte e por outros registros. O cotidiano, portanto, está em constante mudança, pois, sempre que aparece um acontecimento novo capaz de gerar um problema diferente, o modo como agimos frente a ele muda de feição.

Portanto, imbricadas com a cotidianidade atuam forças sociais objetivas (LANA, 2008, p. 231) que anunciam transformações do ponto de vista qualitativo, no modo de vida, nas relações entre os homens. Para o filósofo húngaro, essas forças sociais objetivas podem ser descobertas e explicadas cientificamente, observando-se suas sucessivas mudanças históricas, como um processo dialético, em que percebemos recuos e avanços.

Na perspectiva do materialismo dialético, Agnes Heller assinala que a vida de todo homem está sempre ligada à cotidianidade, não importando qual seja a sua atividade na sociedade, embora haja alguns momentos em que ele se eleva aos aspectos cotidianos (HELLER, 2008, p. 31). Nesse caso, a historiadora ressalta a relação entre a vida cotidiana e o homem, explicitada primeiramente por Georg Lukács. De acordo com a maneira que o homem se relaciona com o seu cotidiano, ele pode ser "homem inteiro" ou "homem inteiramente" 
(HELLER, 2008, p. 31)2. Aquele está associado às diversas atividades que exerce comumente no cotidiano. Logo, na vida cotidiana o "homem inteiro" coloca-se espontânea e genericamente diante dos afazeres do dia-a-dia. Assim, o "homem inteiro" é o homem da cotidianidade, que é, ao mesmo tempo, atuante e fruidor, ativo e receptivo. Participando, dessa forma, das relações cotidianas em que põe todas as suas habilidades físicas e intelectuais, concretas e subjetivas, individuais e sociais, o "homem inteiro" fica impossibilitado de dedicar-se a um elemento só, de forma aguçada e intensa.

Ao passo que o "homem inteiramente", afastando-se da vida cotidiana heterogênea em que atuam vários elementos (trabalho, lazer, a vida social e a vida privada etc.), concentra-se intensamente em uma única atividade. Nesse momento, a percepção e a destreza aumentam sua capacidade de compreensão e análise sobre o objeto ao qual dedica tempo exclusivo. As atividades correspondentes ao "homem inteiramente" são, por exemplo, a arte e a ciência. Estas, entretanto, referem-se ao cotidiano, pois é neste que podemos perceber as ações dos homens e suas relações com o mundo.

No caso da arte, podemos pensá-la como um processo de interação entre o artista e os apreciadores. Ela não pode separar-se de suas funções na sociedade, bem como do contexto social da produção e da recepção. Nesse sentido, o "homem inteiramente" leva sua experiência de vida para o fazer estético.

A dialética da contrariedade entre a vida cotidiana e a arte é sempre uma dialética histórico-social. Ambas atividades inserem-se em situações concretas, históricas e socialmente objetivas, a partir das quais podemos observar o comportamento e o pensamento dos sujeitos envolvidos. Durante o processo da imaginação criadora, o artista afasta-se da cotidianidade numa tentativa de compreendê-la melhor para, em seguida, produzir imagens, símbolos e metáforas que, embora possam referir-se ao mundo concreto, permanecem em outra dimensão, na esfera estética. Nesse momento, o artista identifica-se com o “homem inteiramente”, referido por Georg Lukács e Agnes

\footnotetext{
2 Ver também o capítulo "El medio homogêneo, elhombreentero y elhombreenteramente". In: LUKÁCS. Estética 1. La peculiaridad de lo estético. Volume 2. 1965, p. $318-350$.
} 
Heller, diferente do "homem inteiro", que atua dispersa e despreocupadamente nas atividades cotidianas.

A fim de clarear melhor essas categorias lukacsianas, tomamos como exemplo a figura de Isaías Caminha, narrador-personagem do escritor Lima Barreto. Ele torna-se exemplo de "homem inteiramente" no momento em que narra sua vida na sociedade carioca, pois se volta para o cotidiano de suas ações em coletividade numa condição de reflexão do mundo e de si mesmo, que evidencia seu modo de olhar as coisas, sua posição ética do mundo. Ao narrar, ele percebe o real com mais criticidade. Elabora, por meio da palavra, uma percepção própria do cotidiano. Com esse recurso, o autor Lima Barreto objetiva, no plano estético, a contradição dialética entre o "homem inteiro" e o "homem inteiramente", que está no cerne do ser social. Não obstante parta da imediata cotidianidade, o narrador-personagem avança para o perfil de "homem inteiramente" no ato da escrita, porque considera elementos histórico-sociais para narrar sua vida em sociedade.

Num discurso mesclado de objetividade e ressentimento (subjetividade), Bentinho, no romance Dom Casmurro, de Machado de Assis, ao relatar os episódios de sua vida, o faz com a consciência de escritor. Nesse sentido, constrói uma casa no bairro Engenho Novo, idêntica àquela em que morara quando criança, na antiga Rua de Matacavalos, a fim de facilitar a memória da trajetória humana na vida cotidiana. Aqui, também encontramos a figura do "homem inteiramente" que ganha a alcunha de "Dom Casmurro", justamente porque se afasta da cotidianidade com o propósito de objetivá-la de outro modo, a partir da elaboração prospectiva da imaginação que se alimenta em grande parte dos resíduos acumulados pela memória.

Bastam esses dois exemplos para percebermos que a linguagem literária tanto instiga o novo como também conserva o velho. Nesse complexo, ela joga um papel decisivo para a criação de imagens do mundo objetivo. Ela é mediadora da relação entre o saber estético e o saber cotidiano.

Por isso, historicizar o cotidiano representado na literatura equivale a compreender a experiência humana vivida com ideias, necessidades, sentimentos, razão. Dessa maneira, é possível recuperar a contradição das ações humanas, procurando entender por que determinado processo tomou um rumo e não outro. A partir do estudo do cotidiano na literatura, podemos 
compreender "as mediações sociais continuamente improvisadas no processo global de tensões e conflitos que compõem a organização das relações de produção, o sistema de dominação e de estruturação do poder" (VIEIRA, 2007, p. 11).

Ao escrever uma obra literária, o autor deixa em registro especial seu testemunho da história. Com ela, podemos entender a trajetória dos homens vivendo as várias dimensões do cultural e do social, segundo os hábitos cotidianos dos personagens. Estudar o cotidiano nessa perspectiva significa “apreender e incorporar a experiência vivida (inclusive a do autor), é perceber homens e mulheres não como sujeitos passivos e individualizados, mas como pessoas que vivem situações e relações sociais específicas, com necessidades e interesses e com antagonismos" (VIEIRA, 2007, p. 18). Isso porque a criação literária, notadamente o romance, oferece um sentido inteligível para o leitor em virtude de configurar esteticamente as relações objetivas e subjetivas das pessoas em sociedade. Assim, estudar o cotidiano na literatura nos possibilita compreender como se dão as transformações nos comportamentos, hábitos de vida, modos de pensar e agir, mudanças nas concepções estéticas, enfim, nas práticas culturais, gerando no homem da época certa perplexidade frente àquilo que lhe está posto.

Nesse sentido, Maria Vieira designa muito bem o papel da literatura como testemunho importante da história:

A literatura, dessa forma, expressa relações sociais propostas e, ao mesmo tempo, modela formas de agir e pensar. É um objeto privilegiado para alcançar mudanças não apenas registradas pela literatura, mas principalmente, mudanças que se transformam em literatura pois, mais do que dar um testemunho, ela revelará momentos de tensão. Ela pode expressar possíveis não realizados. Oferece uma avaliação do real na medida em que tem uma visão problemática da realidade. Nessa avaliação acaba selecionando a existência de elementos que obstaculizam a realização das propostas e elementos que ajudam (VIEIRA, 2007, p. 21).

Logo, o complexo de elementos expressos pela literatura, decerto, evidencia práticas culturais em uma dinâmica com capacidade de oferecer ao 
historiador uma fonte riquíssima de uma época e de um espaço humanizados. O gênero romanesco, sendo uma forma literária específica, sugere a figuração de complexas paisagens sociais ${ }^{3}$ em que o homem exerce suas atividades diárias, apaixonando-se, desiludindo-se, transformando-se, resignando-se, fechando-se no interior de si mesmo, curvando-se sobre suas conjeturas, esperanças, angústias, desilusões.

A análise da representação do cotidiano na literatura pretende compreender de que forma os autores narram práticas comuns, experiências particulares, as solidariedades e as lutas que organizam o espaço aonde essas narrações vão descortinando possibilidades de ação e pensamento. Com isso, podemos interpretar as práticas da cidade, na relação entre a rua e o espaço privado da casa. Para Michel de Certeau, “o espaço é um lugar praticado” (2008, p. 202), ou seja, seu significado e valor se dão pelas experiências cotidianas e pelo modo como as pessoas se reapropriam do espaço dado. Conforme assinala Michel de Certeau, a literatura configura-se, sim, como uma prática sociocultural que evidencia outras experiências ou maneiras de fazer:

Enquanto indícios de singularidades - murmúrios poéticos ou trágicos do dia-a-dia - as maneiras de fazer se introduzem em massa no romance ou na ficção. Assim, em primeiro lugar o romance realista do século XIX. Essas maneiras encontram aí um novo espaço de representação, o da ficção, povoado por virtuosidades cotidianas para os leitores, as assinaturas das micro-histórias de todo o mundo (CERTEAU, 2008, p. 142).

O entrecho supracitado expressa bem o motivo da nossa pretensão em estudar o cotidiano na literatura. Sendo a ficção um espaço de representações culturais ${ }^{4}$, debruçaremo-nos sobre os romances de Machado de Assis e os de Lima Barreto, a fim de historicizar alguns elementos da cultura

\footnotetext{
${ }^{3}$ Sobre o tema da paisagem social, humana e estética ver: SOARES, José Wellington Dias. "A paisagem no espaço romanesco de Lima Barreto". In: Lima Barreto: Entre a fiç̧ão e a história. Fortaleza: Edições Demócrito Rocha, 2007.

${ }^{4}$ A propósito, do conceito de "representações culturais", ver por exemplo: PESAVENTO, Sandra Jathay. "Cultura e Representações, uma trajetória". In: Anos 90, Porto Alegre, v. 13, n. 23/24, jan./dez., 2006, p. 46.
} 
carioca $^{5}$ nos fins do século XIX. As narrativas romanescas exercem também o papel cotidiano que sugere os lugares e os sujeitos que dão sentido a esses lugares, semelhante aos relatos segundo Michel de Certeau. Elas, portanto, são fundadoras de espaço. Enfim, a ficção - o romance e o conto para falarmos de gêneros literários modernos - configura com seu poder imagético uma sociedade que representa gente viva e dela faz as suas representações.

Há, entretanto, uma diferença fundamental, que precisa ser esclarecida a esse respeito, entre o fazer literário e as práticas cotidianas, ainda que dialeticamente estas sejam representadas pela ficção e o fazer literário exista enquanto uma realidade também cultural. Assim, enquanto a cotidianidade, conforme explica Michel de Certeau, é estabelecida pelo ocasional e num tempo acidental, cujos atos de pensamento são dispersos (2008, p. 311); na ficção as práticas cotidianas são redimensionadas, uma vez que o tempo é reorganizado pela narrativa. Aqui não há imprevisto ou acidente não pensado.

O estudo da cotidianidade, nos romances dos escritores Machado de Assis e Lima Barreto, incentiva-nos também a lançar um olhar mais demorado sobre a significação do político no âmbito do cotidiano, "no qual se desenvolvem múltiplas relações de poder" (MATOS, 2002, p. 9). Nesse caso, o político enquanto esfera pública é uma presença constante nos hábitos das casas cariocas nos fins do século XIX, cuja significação revela uma participação um pouco mais descentralizada. A partir de então, com a formação mais nítida de uma classe burguesa e liberal, as discussões políticas surgem não apenas nos bailes aristocráticos, mas também durante jantares e comemorações pequenoburgueses, ou ainda mesmo durante uma ou outra partida de voltarete, jogo de baralho com quarenta cartas muito conhecido na época.

Então, ao invés do "caráter histórico da moderna separação entre as esferas pública e privada, cujo objetivo seria a ocultação das tensões e de uma dinâmica de poder que age em ambos" (MATOS, 2002, p. 10); nossa investigação sobre a representação do cotidiano e seu aspecto histórico-cultural pretende

\footnotetext{
${ }^{5}$ Entendo por "cultura carioca" um conjunto de valores, tradições, práticas e representações partilhadas e sempre em construção, que expressa uma identidade coletiva do povo carioca nos fins do século XIX e início do XX. As práticas políticas, os hábitos, os discursos, as religiões e os espaços são alguns elementos que ajudam a objetivar a cultura carioca.
} 
revelar a imbricação dessas esferas, em que os conflitos ordinários nos dizem muito das condições materiais e das práticas culturais da sociedade carioca. O nosso foco ou recorte do objeto de estudo gira em torno do cotidiano urbano do Rio de Janeiro, antiga capital do Brasil, e em experiências porta adentro.

Não obstante alguns historiadores tenham identificado certa atmosfera de alienação, propiciada pela rotina, pela exploração do trabalho e por um espaço sufocante e estático, concordamos com a seguinte afirmação de Maria Matos:

\begin{abstract}
Ao contrário do que alguns apontam, a história do cotidiano não é um terreno relegado apenas aos hábitos e rotinas obscuras. As abordagens que incorporam a análise do cotidiano têm revelado todo um universo de tensões e movimento com uma potencialidade de confrontos, deixando entrever um mundo onde se multiplicam formas peculiares de resistência/luta, integração/diferenciação, permanência/transformação, onde a mudança não está excluída, mas sim vivenciada de diferentes formas. Assim, não se pode dizer que a história do cotidiano privilegie o estático, já que tem mostrado toda a potencialidade do cotidiano como espaço de resistência ao processo de dominação (MATOS, 2002, p. 26).
\end{abstract}

Assim, as tensões, o movimento, os confrontos, as formas de resistência/luta, a integração/diferenciação, a permanência/transformação são elementos presentes constantemente no cotidiano. Diante da exploração do homem pelo homem, de situações adversas e da luta pela sobrevivência, o cotidiano aparece como um espaço de resistência, de liberdades, em que as pessoas utilizam-se da criatividade e, muitas vezes, da solidariedade como uma espécie de equalização de forças.

No espaço estético da narrativa romanesca, que se encontra na dimensão ficcional, na imaginação criadora, temos a representação imagética do espaço cotidiano. Neste como naquele, existem uma ação política, uma força social e uma prática cultural, envolvidas em uma só esfera dinâmica, a realidade. Para compreender o papel do historiador frente a esse objeto como um campo de múltiplas possibilidades de interpretações, é necessário mais uma vez recorrer às palavras de Maria Matos, ainda que a citação seja extensa: 
O historiador do cotidiano tem como preocupação restaurar as tramas de vidas que estavam encobertas, procurar no fundo da história figuras ocultas, recobrar o pulsar no cotidiano, recuperar sua ambiguidade e a pluralidade de possíveis vivências e interpretações, desfiar a teia de relações cotidianas e suas diferentes dimensões de experiência, fugindo dos dualismos e polaridades e questionando as dicotomias. Ao recuperar o processo histórico, pretende perceber suas mudanças e permanências, descontinuidade e fragmentação, as amplas articulações, as infinitas possibilidades dessa trama multidimensional, que se compõem e recompõem continuamente (MATOS, 2002, p. 26-27).

Nesse sentido, o trabalho do historiador do cotidiano se identifica, em alguns aspectos, com a produção criativa do romancista, pois ambos pretendem atribuir sentido à vida cotidiana, a partir da narrativa. Não é nossa intenção aprofundar a discussão sobre as especificidades da narrativa historiográfica do cotidiano e da narrativa ficcional, ainda que esse assunto possa aparecer no desenvolvimento argumentativo dos próximos capítulos. Entretanto, ressaltamos por enquanto que ambas narrativas se encontram num ponto específico, qual seja, em reorganizar o mundo cotidiano para descortinar a vida em sua complexidade. É evidente que o olhar, seja do historiador seja do romancista, nunca será suficiente para oferecer a seus respectivos leitores a totalidade do mundo humano, mas existem narrativas cujos recortes do particular sugerem experiências humanas universais.

Por conseguinte, as expressões referidas no entrecho supracitado, tais como "tramas de vidas", "o pulsar do cotidiano", "ambiguidade", "pluralidade", "possíveis vivências e interpretações", "teia de relações" e "dimensões de experiências" correspondem tanto ao objeto de estudo do historiador do cotidiano, como também às perspectivas miméticas para a criação estética. Nesses termos, o cruzamento das atividades associadas a esses dois ramos do conhecimento (o histórico e o literário) são ressaltados aqui como nossa preocupação constante.

Ainda no que tange à compreensão da politização do privado (a casa) e da privatização do público (a rua), é possível dizer que a literatura, sobretudo o romance, preenche a lacuna deixada pela falta de fontes relativas ao 
cotidiano. Nesse sentido, é indiscutível a contribuição que ela oferece à produção historiográfica contemporânea sobre o cotidiano anterior, pois amplia o campo de investigação das visões do passado nessa perspectiva.

Considerando o cotidiano não como um fenômeno natural e imutável, mas como uma atividade social e dinâmica, o historiador deve estudá-lo mais do ponto de vista qualitativo e analítico do que descritivo. Além disso, precisa relacioná-lo com acontecimentos mais conjunturais e amplos, de modo a contextualizá-lo com as transformações culturais, sociais, políticas e econômicas.

Ao analisar as obras romanescas dos escritores cariocas em causa, poderemos observar, na perspectiva do cotidiano entendido aqui, os personagens que representam pessoas comuns e suas estratégias, sua capacidade de explorar e suportar as inconsistências da sociedade e de encontrar brechas através das quais possam se introduzir no cenário social relevante, ou frestas em que consigam sobreviver com dignidade. Além do que, poderemos verificar como o cotidiano das personagens/pessoas está vinculado à expansão urbana do Rio de Janeiro, no final do século XIX e início do XX, compreendendo o ritmo de crescimento da cidade e o ritmo de vida nela. Desse modo, investigaremos elementos que mostrem, na criação literária, a latência de um espaço entre a casa e a rua onde ocorrem trocas permanentes de experiências, estabelecendo relações dinâmicas e criando laços de solidariedade e estratégias de sobrevivência.

Sob o foco da figuração das atividades sociais dos personagens na ficção, estudaremos a maneira como se deu a organização do cotidiano de homens e mulheres, que se dedicavam a diversas ocupações; quais as articulações possíveis entre as relações sociais, de gênero e étnicas, assim como práticas culturais e modos de vida, visando perceber a forma de organização dessas atividades e a estruturação do seu tempo-espaço dentro da casa e nas ruas. Portanto, pretendemos refletir, a partir do cenário romanesco de Machado de Assis e de Lima Barreto, sobre a singularidade do cotidiano da casa e da rua, onde conviviam criados e patrões, compreendendo a organização do trabalho no Brasil do século XIX. Assim, poderemos penetrar na discussão sobre a organização do tempo e do espaço no universo porta adentro, onde, ao contrário das transformações urbanas mais explícitas, as alterações 
qualitativas na vida das pessoas viabilizam-se de forma velada e sutil (MATOS, 2002, p. 115).

Conforme assinalam Georg Lukács e Agnes Heller, ainda que em campos diferentes do conhecimento, há uma dimensão particular no contexto da vida cotidiana que se entrelaça com situações compartilhadas. Nesse fluxo dinâmico e indissociável, a cotidianidade é entendida como a relação permanente entre a particularidade e a universalidade. Essa relação não é pensada como polos dicotômicos, uma vez que uma não elimina a outra. Ao contrário, elas convivem ao mesmo tempo no ser humano, que vivendo os meandros ontológicos, segundo os preceitos marxianos ${ }^{6}$, é também um ser social. Além do que, é preciso contextualizar o olhar dos romancistas em análise em relação ao cotidiano que os circundava, inclusive o olhar de cronista que possui preocupação mais especial com os hábitos particulares do dia-a-dia. Este, pois, tornava-se objeto constante de suas observações e análises nos jornais da época. Decerto, Machado de Assis e Lima Barreto lançaram, cada um a seu jeito, um olhar perspicaz e crítico sobre a organização da sociedade carioca da época em que escreveram, e sobre suas instituições (culturais, políticas, educacionais, econômicas etc.). Dessa forma, buscaram captar os fragmentos da realidade para os seus romances.

Outros autores, inclusive no âmbito internacional, também se utilizaram, com semelhante maestria, desse recurso, tais como Charles Baudellaire, Edgar Allan Poe, Emilé Zola, Charles Dickens, Honoré de Balzac, Victor Hugo e Dostoièvski. Todos eles, conhecidos e lidos pelos nossos romancistas, trouxeram relatos interessantes do panorama urbano de suas respectivas cidades. Nunca, até então, o processo de criação literária havia conciliado tão evidentemente a realidade exterior em seus romances como a ficção oitocentista. Certamente esses literatos tenham sido instigados a pensar um cotidiano que se deixava afetar sensivelmente pela Modernidade. Assim, viram com perplexidade um complexo de transformações e, em seguida, de acomodações do cotidiano urbano, a partir do qual foram percebidas várias reformas e ações higienistas, de alargamento de avenidas para acelerar o fluxo

${ }^{6}$ Ver a esse propósito: LUKÁCS, Georg. Os princípios ontológicos fundamentais de Marx. São Paulo: Editora Ciências Humanas, 1972. 
de transportes, de aglomeração de pessoas em condições precárias; sem mencionar as mudanças de hábito e pensamento. Logo, a forma de viver se modificava muito rápido nas grandes cidades capitalistas.

Nesse sentido, o deslocamento rápido e os diferentes modos de vida fazem a orientação do espaço urbano e a noção de tempo social assumirem perspectivas diversas diante da percepção do observador/escritor. Enfim, os cotidianos da casa, da rua, da praça, da avenida, das periferias, do centro urbano, do trabalho, das lojas da Rua do Ouvidor sugerem uma dinâmica no modo de vida das pessoas, bem como implicações no entendimento a respeito das categorias tempo e espaço, tão importante para o ser humano. É certamente a combinação de tantas práticas cotidianas distintas que viabilizam as manifestações de culturas plurais.

O estudo do cotidiano da sociedade carioca, através da perspectiva literária, é uma maneira de historicizar a noção mesma da vida cotidiana. Com isso, é possível entendermos o processo de uma formação social específica. Por conseguinte, a vida privada e familiar, as atividades ligadas à manutenção dos laços sociais, ao trabalho doméstico e às práticas de consumo, percebidas na narrativa de ficção, dizem-nos muito sobre um quadro histórico particular.

Referindo-se às práticas cotidianas do século XVIII, época em que, segundo a autora, observamos mudanças significativas nas formas de vida cotidiana, Mary Del Priore assinala que "é no movimento de uma transformação profunda das relações sociais que a 'vida cotidiana' vai se redefinindo e tomando as formas e o conteúdo atuais" (PRIORE, 1997, p. 337). Dessa forma, subentende-se que existe uma relação dialética entre as relações sociais e as maneiras de viver no cotidiano, pois aquelas se dão a perceber e a sentir nos hábitos do dia-a-dia. Sem isso, não seria possível refletir sobre as relações sociais e alcançar transformá-las continuamente. No centro desse processo, há elementos que se destacam como agentes transformadores, tais como o trabalho, a ciência e a arte; estas duas últimas como reflexo da realidade e aquele como prática capaz de redefinir constantemente a relação entre o sujeito e o mundo. Por isso, não excluímos da nossa análise os campos do econômico, do político e do cultural na sua dimensão ativa e inovadora. 
A nossa perspectiva de pesquisa, então, não se afasta dos preceitos metodológicos da Escola dos Annales, pelo menos na sua primeira fase, pois como afirma Mary Del Priore:

Para a Escola dos Annales: o cotidiano e o estudo da vida privada são, essencialmente, uma maneira de abordar a história econômica e social. [...] a história da vida cotidiana não é definida somente pelo estudo do habitual por oposição ao excepcional (ou ao factual), nem é, tampouco, concebida como a descrição do cenário de uma época (PRIORE, 1997, p. 385).

Desse modo, não buscamos dicotomias como forma de explicação do cotidiano, mas uma interpretação acerca do movimento de atitudes e gestos que significam uma produção ativa e criativa da existência. Nessa dinâmica, pensamos sobre aquilo que muda historicamente no cotidiano e sobre os múltiplos deslocamentos em que é possível vislumbrar certa ruptura das relações de dominação.

Tanto a obra de Machado de Assis quanto a de Lima Barreto são consideradas referências na literatura brasileira, pois cada uma, a seu modo, revela tensões ideológicas entre classes sociais a partir do cotidiano delas. Enquanto este faz ressoar a voz das minorias, aquele coloca em xeque a credibilidade dos poderosos, através dos interesses da emergente sociedade capitalista, em um dos seus núcleos mais representativos: a família burguesa. Em outras palavras, eles abordam situações do cotidiano, trazendo para as obras vozes caladas, ou vozes que se apropriam de um discurso criado para se apresentarem.

Machado de Assis explorou, em sua vasta produção literária, temas reveladores do drama humano, desvendando, ao lado de um Brasil que ingressava no progresso, os interesses e a malícia que se escondiam por detrás dos bastidores da classe alta. São representantes desta, portanto, que servirão ao escritor como modelos para a criação de seus personagens: os empresários, os aristocratas, os negociantes de escravos e as suas esposas e filhos entediados de ociosidade.

Frente a esse painel de "seres", ou seja, de personagens/pessoas, criados a partir do cotidiano e da experiência do escritor, mas também da 
imaginação, embora ele tivesse como modelo as leituras de outros textos, perpassam conflitos, que, em muitos casos, são aplacados através de um discurso camuflado, irônico e subentendido. São, entretanto, reveladores de aspectos sociais, ideológicos, políticos e culturais, muitas vezes, não percebidos por alguns leitores.

Lima Barreto, por sua vez, em sua obra, interpreta o cotidiano de maneira bastante distinta. Logo, ele contribuirá para dar outra feição à sua produção ficcional. Nesta, encontramos um discurso literário que anuncia temas contextualizados com a República brasileira, denunciando diretamente a burguesia ascendente, em favor daqueles que vivem às margens da sociedade, na condição de ex-escravos, os pequenos funcionários públicos, os trabalhadores, as mulheres oprimidas pelo marido centralizador, entre outros estratos subalternos.

\section{Referências}

CERTEAU, Michel de. A invenção do cotidiano: 1 . Artes de fazer. 14 a ed. Trad.: Ephraim Ferreira Alves. Petrópolis, Rio de Janeiro: Vozes, 2008.

HELLER, Agnes. O cotidiano e a história. Trad.: Carlos Nelson Coutinho e Leandro Konder. São Paulo: Paz e Terra, 2008.

LANA, Lígia Campos de Cerqueira \& FRANÇA, Renné Oliveira. "Do cotidiano ao acontecimento, do acontecimento ao cotidiano". In: Revista da Associação Nacional dos Programas em Comunicação/E-compós. Brasília. V. 11, n.3, set/dez, 2008. Disponível in: www.e-compós.org.br

LUKÁCS, Georg. Estética 1: La peculiaridad de lo estético. Volumes 1 e 2. Traducción de Manuel Sacristán. Barcelona: EdicionesGrijalbo, 1965.

LUKÁCS, Georg. Introdução a uma estética marxista: Sobre a categoria da particularidade. Trad.: Carlos Nelson Coutinho e Leandro Konder. Rio de Janeiro: Civilização Brasileira, 1968.

LUKÁCS, Georg. Os princípios ontológicos fundamentais de Marx. São Paulo: Editora Ciências Humanas, 1972.

MATOS, Maria Izilda Santos de. Cotidiano e cultura: história, cidade e trabalho. Bauru, SP: EDUSC, 2002. 
PESAVENTO, Sandra Jathay. "Cultura e Representações, uma trajetória”. In: Anos 90, Porto Alegre, v. 13, n. 23/24, jan./dez., 2006.

PRIORE, Mary Del. "História do cotidiano e da vida privada”. In: CARDOSO, Ciro Flamarion; VAINFAS, Ronaldo (Org.). Domínios da história: ensaios de teoria e metodologia. Rio de Janeiro: Campus, 1997.

RANCIÈRE, Jacques. A partilha do sensível: estética e política. Trad.: Mônica Costa Netto. São Paulo: EXO experimental org. Ed. 34, 2005.

SOARES, José Wellington Dias. Lima Barreto: Entre a ficção e a história. Fortaleza: Edições Demócrito Rocha, 2007.

VIEIRA, Maria do Pilar de Araújo et al. A pesquisa em história. 5. ed. São Paulo: Ática, 2007.

Recebido em 29 de abril de 2020.

Aceito em 20 de junho de 2020. 
